\title{
Proposed protocol with transcutaneous electrical nerve stimulation for the treatment of non-specific chronic low back pain
}

\section{Propuesta de protocolo con estimulación nerviosa eléctrica transcutánea para el tratamiento del dolor lumbar crónico inespecífico}

\author{
CORONA-BRISEÑO, Agustin†* \\ Universidad del Futbol y Ciencias del Deporte, San Agustín Tlaxiaca, Hidalgo, México.
}

ID $1^{\text {st }}$ Author: Agustin, Corona-Briseño / ORC ID: 0000-0003-2954-5605

Received: September 09, 2019; Accepted: November 04, 2019

\begin{abstract}
The low back pain is defined as pain or discomfort in an area around the upper portion of T12 and bottom of the gluteal fold, with functional limitation. It is the second most frequent cause of medical consultation at first care level. Objective: propose a protocol through electrotherapy utilizing transcutaneous electrical nerve stimulation (TENS) for the treatment of nonspecific chronic low back pain; It seeks to exemplify in a clear and concise method the type of frequency, pulse duration, intensity, placement of the electrodes, as well as duration and periodicity of the sessions to obtain the desired analgesic effect. Methodology: Quantitative type, non-experimental, retrospective, transversal and descriptive. Contribution: The application of Transcutaneous Electrical Nerve Stimulation in high and low frequency in the same session is effective in the treatment of nonspecific chronic low back pain because the lumbar mobility increases, the intensity of the pain decreases and therefore the degree of disability of patients.
\end{abstract}

Nonspecific low back pain, Protocol, TENS

\begin{abstract}
Resumen
La lumbalgia se define como dolor o malestar en un área alrededor de la porción superior de T12 e inferior al pliegue de los glúteos, junto con limitación funcional. Es la segunda causa más frecuente de consulta médica en el primer nivel de atención. Objetivo: proponer un protocolo mediante electroterapia empleando estimulación nerviosa eléctrica transcutánea (TENS) para el tratamiento del dolor lumbar crónico inespecífico; se busca ejemplificar de forma clara y concisa el tipo de frecuencia, duración de pulso, intensidad, colocación de los electrodos, así como la duración y periocidad de las sesiones para obtener el efecto analgésico deseado. Metodología: Tipo cuantitativo, no experimental, retrospectivo, transversal y descriptivo. Contribución: La aplicación de Estimulación Nerviosa Eléctrica Transcutánea de alta y baja frecuencia en una misma sesión es eficaz en el tratamiento del dolor lumbar crónico inespecífico ya que aumenta la movilidad lumbar, disminuye la intensidad del dolor y por ende el grado de incapacidad de los pacientes.
\end{abstract}

Dolor lumbar inespecífico, Protocolo, TENS

Citation: CORONA-BRISEÑO, Agustin. Proposed protocol with transcutaneous electrical nerve stimulation for the treatment of non-specific chronic low back pain. ECORFAN Journal-Bolivia. 2019. 6-11: 20-29.

\footnotetext{
* Correspondence to Author (aguscorona10@ gmail.com)

$\dagger$ Researcher contributing as first author.
} 


\section{Introduction}

Low back pain is the second most frequent cause of medical consultation in the first level of care, between 60 and $80 \%$ of the population will experience this problem at some time in their life, which will condition $40 \%$ of all work absences, decreasing the productivity of those affected. The prevalence of this health problem is increasing by $11.4 \%$ per year, so it is a pathology that occurs very often in health services.

Low back pain is defined as pain or discomfort in an area around the upper portion of T12 and lower than the buttock fold, along with functional limitation. This concept does not apply to a specific low back pain and is independent of the cause that gave rise to it. (1)

Three types of low back pain are distinguished based on the time of evolution:

1. Acute low back pain: lumbar pain that is less than six weeks old.

2. Subacute low back pain: if pain in the lower back remains between six and twelve weeks.

3. Chronic low back pain: when low back pain persists for more than 12 weeks.

According to the possible origin of low back pain, we can also classify it into:

1. Non-specific low back pain: this is the pain in which there is no apparent cause.

2. Low back pain associated with radiculopathy: that discomfort with neurological involvement that radiates to one of the two lower extremities.

3. Secondary low back pain: the main causes of this type of pain would be infections, tumors, inflammatory diseases such as ankylosing spondylitis, fractures, cauda equina syndrome, among others. (2)

The treatment of low back pain consists in reducing pain, improving functionality and quality of life, as well as avoiding recurrences. Pharmacological treatment should be based on the analgesic ladder of the World Health Organization (WHO).
Various groups of analgesics are used, from non-steroidal anti-inflammatory drugs (NSAIDs), muscle relaxants, antidepressants and local anesthetics that have demonstrated efficacy for such ailment. In relation to nonpharmacological treatment, the main goal is to try to reduce or eliminate pain, in addition to ensuring the return to daily activities and work. There are several studies that report a significant clinical improvement with rehabilitation exercises, however, few studies prove its effectiveness in alternative intervention methods such as: low intensity laser, transcutaneous electrical nerve stimulation, thermotherapy, lumbar traction and / or massage leaving its effectiveness is in doubt, so it is necessary to demonstrate that treatment alternatives improve functionality in addition to reducing the risk of polypharmacy or complications. (3)

The TENS application has a wide variety of parameters such as electrode placement, waveform, frequency, pulse width, current intensity, as well as the duration and frequency of the sessions. The optimization of these parameters is essential to achieve the desired therapeutic effects, however, existing studies have great variability in the use of these parameters, which is one of the reasons why the effectiveness of TENS has been controversial. (4).

When applying TENS, patients can develop tolerance to stimulation, similar to the tolerance that develops to opiates. Tolerance determines the need for higher intervention doses to achieve the same effect. Patients may develop TENS tolerance from the fourth or fifth day of stimulation. It has been shown that frequency modulations, similar to those used to prevent accommodation, delay tolerance to TENS-induced analgesia. (5)

The objective of this work is to propose a protocol by electrotherapy using transcutaneous electrical nerve stimulation (TENS) for the treatment of nonspecific chronic low back pain. It seeks to exemplify in a clear and concise manner the type of frequency, pulse duration, intensity, placement of the electrodes, as well as the duration and periodicity of the sessions to obtain the desired analgesic effect. 
Annex to the aforementioned, another purpose is to clarify whether the phenomenon of TENS tolerance exists or not, as well as to demonstrate the impact of said therapeutic current in the short and long term in the treatment of chronic low back pain since up to now its utility in this condition is controversial.

\section{Central awareness}

When a tissue is damaged and the pain persists for a few days, mechanisms of adaptation of the nociceptors and the nociceptive response to damage occur. This process is called primary hyperalgesia or peripheral sensitization and represents a protective action of the human body against possible future damage. Secondary hyperalgesia or central sensitization (SC) refers to the process of increasing the response in the dorsal horn, located in the nociception processing segments. Peripheral sensitization is temporary, $\mathrm{SC}$ is a process that encompasses the central nervous system.

Central hyperexcitability is responsible for the amplification of the nociceptive afferent signal that arrives from the periphery, which produces structural modifications such as alterations in genetic regulation and causes the death of inhibitory neurons. Other mechanisms involved in CS are: malfunction of descending pain inhibitory mechanisms and an increase intemporal summation.

The descending pain system is controlled by a correct balance between the inhibitory descending system and the facilitating descending system. A reduction in the control of the descending inhibitory system results in a greater vulnerability of the entire neuroaxis to pain as a result of a generalized induction to hyperalgesia.

Temporal summation is a measure of central mechanisms that is triggered by the application of a sequence of stimuli with the same intensity where there is an increase in painful sensation. In the case of CS this mechanism is altered and results in a facilitation of said summation, which has been observed in patients with chronic musculoskeletal pain.
Transcutaneous electrical nerve stimulation (TENS) is frequently used in patients with chronic pain, its mechanism of action activates the descending inhibitory system, which in turn is activated by the gray periacueductal substance and the ventromedial rostral ganglion of the medulla. Therefore, the TENS current is involved in the mechanisms of SC. (6)

\section{TENS high frequency}

Also known as conventional TENS, it uses twophase pulses of short duration (50-80 microseconds) and high frequency (100-150 pulses per second) with amplitude that produces a comfortable sensation without muscle contraction.

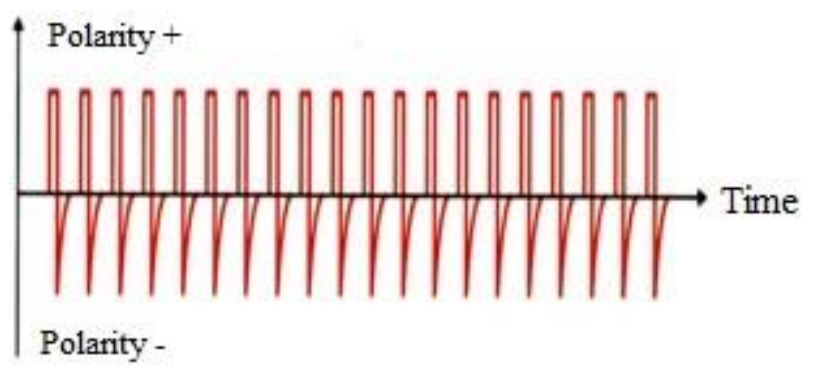

Figure 1 TENS high frequency current Source: Cameron, M. (2019). Physical agents in rehabilitation. Evidence based practice. Barcelona: ELSEVIER

Sensitive electrical stimulation can control pain by activating the non-nociceptor A $\beta$ (A beta) nerves, which inhibits the transmission of harmful signals at the level of the spinal cord. When $A \beta$ activity increases, pain perception is reduced.

Conventional TENS can interrupt the pain-spasm-pain cycle once the stimulation subsides. Pain decreases directly through electrical stimulation, which indirectly reduces muscle spasm, further mitigating pain. (5)

High frequency TENS (TAF) increases the concentration of $\beta$-endorphins in the bloodstream and cerebrospinal fluid, and enkephalin methionine only in the cerebrospinal fluid. The analgesia produced prevents the reduction of hyperalgesia by blocking opioid receptors in the ventromedial rostral medulla (MRV) or spinal cord, or blocks synaptic transmission in the ventrolateral gray periacueductal substance (GSP). 
The reduction of hyperalgesia produced by TAF is avoided by blocking the M1 and M3 muscarinic receptors, and the GABA receptors in the spinal cord. However, blocking serotonin or noradrenergic receptors in the spinal cord has no effect on the reversal of hyperalgesia caused by TAF.

TAF produces analgesia by activating endogenous inhibitory mechanisms in the central nervous system that involve opioid GABA and muscarinic receptors. (7)

\section{Opioid release}

Transcutaneous electrical nerve stimulation can control pain by stimulating the production and release of endorphins and encephalin. These substances known as endogenous opioids act similarly to morphine and modulate the perception of pain by binding to opioid receptors, which activate the descending inhibitory pathways that involve non-opioid systems (serotonin). (5)

\section{TENS low frequency}

It uses a frequency of 2 to 10 pulses per second, long duration amplitude: 200 to $300 \mu$ s (microseconds) with sufficient intensity to produce a motor contraction. Repetitive stimulation of motor nerves increases the production and release of endogenous opiates and increases their ability to bind opioid receptors.

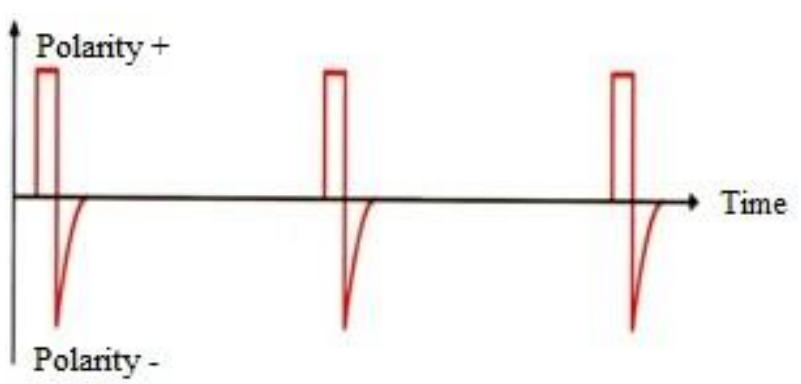

Figure 2 TENS current low frequency

Source: Cameron, M. (2019). Physical agents in rehabilitation. Evidence based practice. Barcelona: ELSEVIER

After a session with low frequency TENS an analgesic effect is exerted for 4-5 hours since this is the average life time of the released endogenous opioids.
Electrical stimulation should not exceed 45 minutes per session because prolonged muscle contraction can lead to late-onset myalgias. (5)

The reduction of hyperalgesia by low frequency TENS (TBF) is avoided by blocking the opioid receptors $\mu$ in the spinal cord or MRV and by synaptic transmission in the ventrolateral GSP. In addition, the reduction of hyperalgesia due to TBF is avoided by blocking serotonin 5-HT2A and 5-HT3, GABA and M1 and M3 muscarinic receptors in the spinal cord, which is associated with increased serotonin release. TBF does not produce analgesia in opioid-tolerant people but TAF does, therefore, TBF uses classical descending inhibitory pathways that include the activating opioid SGP-MRV, GABA, serotonin and muscarinic receptors to reduce the activity of the horn neuron dorsal and subsequent pain. (7)

\section{Reduction of central excitability}

Both TAF and TBF reduce the activity of dorsal horn neurons. In individuals with peripheral inflammation or neuropathic pain, the increased activity of dorsal horn neurons to harmful and harmless stimuli is reduced by both TAF and TBF. At the same time there is a reduction in both primary and secondary hyperalgesia with TAF and TBF, in addition there is a reduction in pain thresholds by pressure not only at the stimulation site, but also at sites outside the application area, implying a reduction of central excitability.

TAF also reduces the sensitization of central neurons and the release of neurotransmitters that excite glutamate and substance $\mathrm{P}$ in the spinal cord's dorsal horn in individuals with inflammation. The reduction of glutamate is avoided by blocking $\delta$ opioid receptors, therefore, a consequence of the activation of the inhibitory pathways exerted by TENS is to reduce the excitation and consequent sensitization of neurons in the spinal cord. Both TAF and TBF have effects at the stimulation site, TAF reduces substance $P$, which increases in the neurons of the dorsal root ganglia after a tissue injury. Blocking peripheral opioid receptors prevents analgesia caused by TBF but not by TAF. Therefore, TENS can also alter the excitability of peripheral nociceptors to reduce afferent entry to the central nervous system. (7) 


\section{Most used scales for pain assessment}

Defining pain and doing it in such a way that it has a unanimous acceptance is complex, since it is an individual and subjective experience, to which is attached the fact that there is no scientific method that makes it measurable. To evaluate it, instruments are used that are easily understandable, of minimal effort for the patient, and that demonstrate reliability and validity.

Although all pain scoring scales are valid, reliable and appropriate for use in clinical practice, the Visual Analog Scale (VAS) has more practical difficulties than the Verbal Score Scale (CVD) or the Numeric Scale (EN). For general purposes, the EN has a good sensitivity and generates data that can be statistically analyzed.

\section{0-10 Numeric Pain Rating Scale}

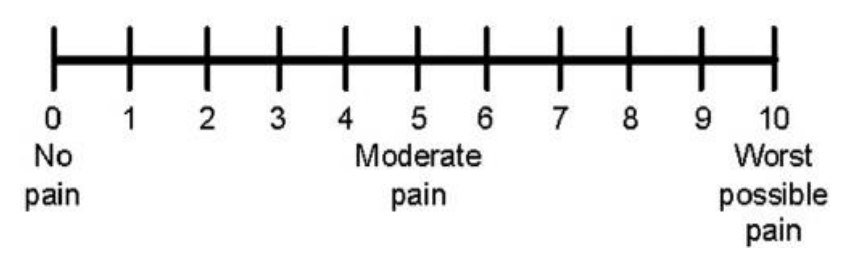

Figure 3 Numerical scale

Source: Swartz, M. H. Treaty of Semiology. History and exploration. Seventh edition. Barcelona 2015

The EN is a numbered range from 0 to 10 , where 0 is the absence of pain and 10 is the greatest intensity of it, the patient selects the number that best assesses the intensity of the symptom. (8)

\section{Oswestry low back pain disability scale}

It is a self-applied questionnaire consisting of 10 questions concerning activities of daily living that can be interrupted or altered by low back pain. Each question has six possible answers that progressively describe a greater degree of difficulty of the activity. The first question refers to the intensity of pain, specifying in different options the answer to taking painkillers. The remaining items include basic activities of daily living that can be affected by pain (personal care, weight lifting, walking, sitting, standing, sleeping, sexual activity, social life and traveling). It is the most used and recommended scale.
The answers are scored from zero to five, giving a maximum score of 50, the total points are multiplied by two and expressed as a percentage. The results are cataloged as follows: no dysfunction $(0 \%)$, minimal dysfunction ( $1 \%$ to $20 \%$ ), moderate dysfunction ( $21 \%$ to $40 \%)$, severe dysfunction (41\% to $60 \%$ ) and disability (greater than 61\%). (9)

\section{Lumbar flexion assessment}

During the life cycle people develop arcs of movement that allow them to be integrated into mechanical tasks of the locomotor system, including those related to the lumbar spine flexion, which involves multiple morphological elements among which are intervertebrales discs, which They allow moderate movements thanks to their flexibility and increased intradiscal pressure. In addition, the type of joints, the elasticity of tissues, tendons, ligaments and the length of the muscles can affect lumbar mobility. (10)

Quantification of spinal mobility is a beneficial component in physiotherapeutic assessment for people experiencing limited spinal mobility as a result of disorders or injuries in the spine. (eleven). In a study evaluating the inter-evaluative reliability and validity of common clinical trials that measure the range of lumbar movement, it was found that the modified Schober maneuver could be the best criterion for measuring the range of lumbar flexion. (10).

\section{Modified Schober Test}

Technique used in the exploration of lumbar mobility, which measures the increase in distance (in centimeters) between 2 defined points on the lower back, which excludes the influence of the hip, pelvis and hamstring joints, which gives excellent inter-evaluation reliability, its use is widely recommended in clinical practice. (10).

A mark is made on the midline at the level of the posterior superior iliac spine (i.e., $\mathrm{S} 2$ ), then a point $5 \mathrm{~cm}$ below and $10 \mathrm{~cm}$ above that mark is indicated. The distance between the three points is measured, then the patient is asked to flex forward and the distance is measured again. (11) 

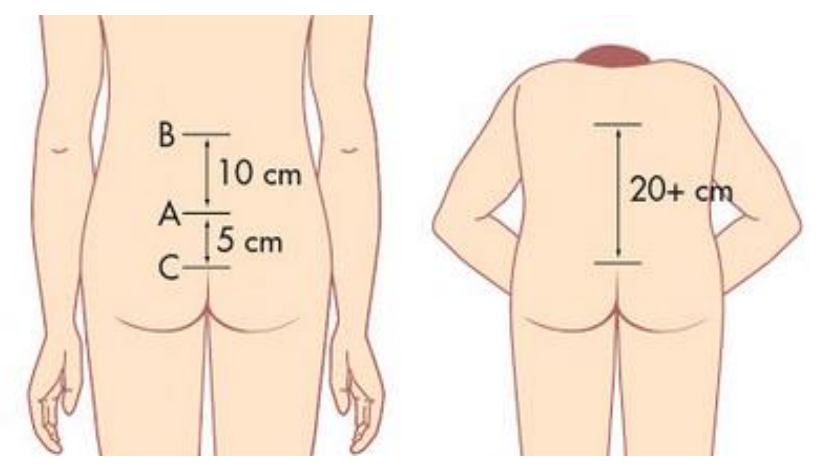

Figure 4 Schober test modified. (A) point between both EIPS; (B) upper point; (C) bottom point

Source: Talley, N. J., \& O'Connor, S. (2013). Clinical examination: a systematic guide to physical diagnosis. Elsevier Health Sciences

The measurement difference between the upper and lower points is an indication of the magnitude of flexion in the lumbar spine. It is expected that, with trunk flexion, the second measurement will increase by at least 5 centimeters compared to the first. If this does not occur, the patient is considered to have a limitation for lumbar spine flexion. (12).

\section{Material and methods}

Twenty people with low back pain were included, of which 15 met the inclusion criteria: low back pain with 3 or more months of evolution and signed informed consent. Patients with unstable arrhythmia, cardiac pacemaker on demand, implantable defibrillator, deterioration of mental status, open wounds in the lumbar area, postoperative lumbar spine carriers carrying some type of electrical conductive surgical material (plates, nails, screws) were excluded, sensitivity impairment, malignant tumors or pregnancy. The materials used for the application of the protocol were: a HomeCare ${ }^{\circledR}$ model M012A 3-section portable physiotherapy stretcher, an Oswestry low back pain scale questionnaire, a Fith by HERGOM ${ }^{\circledR}$ model R12 medical measuring tape, a permanent marker BIC® Marking TM fine point, a Globus ${ }^{\circledR}$ GENESY 3000 electrostimulator and four $4 \times 8 \mathrm{~cm}$ rectangular $\mathrm{KHG}-\mathrm{CM} 4080$ selfadhesive electrodes with cable and PVC coated connector, carbon conductive plate.

\section{Protocol Application}

At the beginning of the session, the patient is asked to assess the intensity of his low back pain according to the numerical scale, then the Oswestry questionnaire is delivered and its filling is requested.
Subsequently, with the patient standing, the marks marking the modified Schober test are marked with the permanent BIC $®$ Marking TM marker, then the Fith by HERGOM ${ }^{\circledR}$ model R12 medical measuring tape is taken, simultaneously, while the patient performs a trunk flexion with the knees extended trying to touch the floor with the fingers, the therapist measures the distance between the upper and lower point previously indicated and records the result.

Then, the patient is placed prone on the stretcher for portable physiotherapy of 3 sections brand HomeCare $\AA$ model M012A, then, with the lumbar area discovered and his previous asepsis, the first rectangular selfadhesive electrode KHG-CM4080 of $4 \times 8 \mathrm{~cm}$ is placed horizontally in the upper portion of $\mathrm{T} 12$ at $3 \mathrm{~cm}$ lateral to the midline, the second electrode is placed at the level of the posterior iliac spine, that is $S 2$, also horizontally at $3 \mathrm{~cm}$ lateral to the midline, both of the right side of the spine. Then, the two remaining electrodes repeat the same placement of the previous ones, now on the left side of the column.

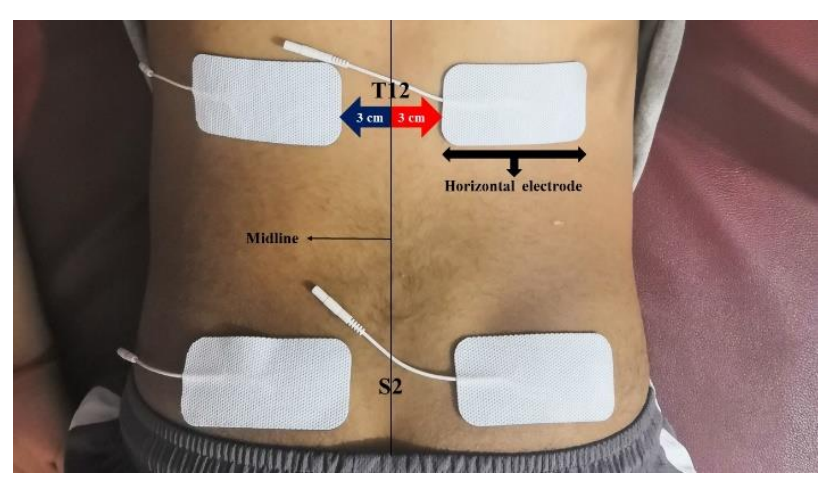

Figure 5 Placement of the self-adhesive electrodes Source: Self Made

Subsequently, channel 1 and 2 of the Globus ${ }^{\circledR}$ GENESY 3000 electrostimulator are taken, the positive $(+)$ pole of channel 1 is placed on the upper right electrode, the cathode (-) of the same channel is placed longitudinally on the lower electrode straight.

The polarity of channel 2 of the electrostimulator is placed equally on the left side: upper (+) anode, lower (-) cathode. 


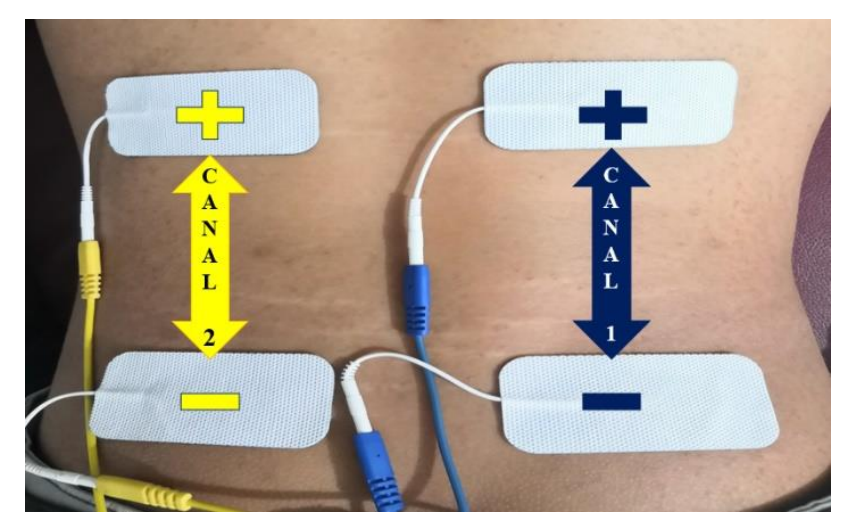

Figure 6 Polarity placement: the blue wire is channel 1 of the electrostimulator and the yellow one is channel 2 Source: Self Made

Then, in the Globus ${ }^{\circledR}$ GENESY 3000 electrostimulator, the high frequency TENS current is selected at $120 \mathrm{~Hz}$ (pulses per second), amplitude of $80 \mu$ s (microseconds), maximum intensity tolerated by the patient without generating pain for 20 minutes. Then, once the high frequency TENS stimulation ceases, in the same position of the patient and placement of both electrodes and electrostimulator polarity, low frequency TENS is applied at $3 \mathrm{~Hz}$ (pulses per second), amplitude of $250 \mu \mathrm{s}$ (microseconds), sensory intensity for 10 minutes.

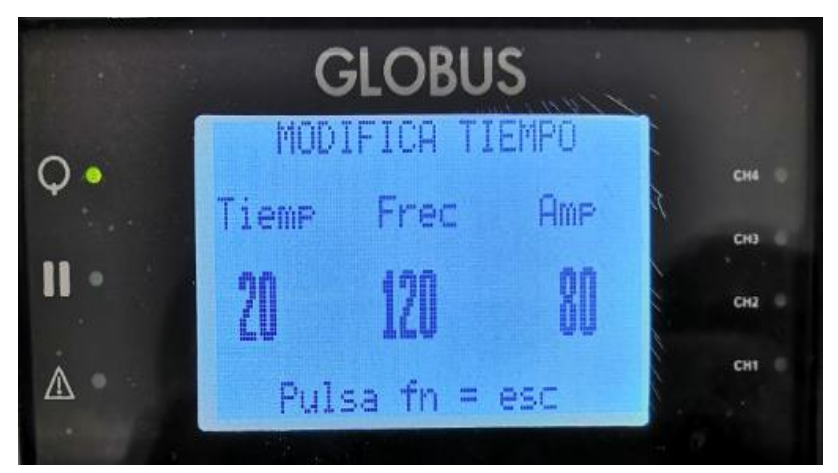

Figure 7 Programming of the electrostimulator: TENS high frequency

Source: Self Made

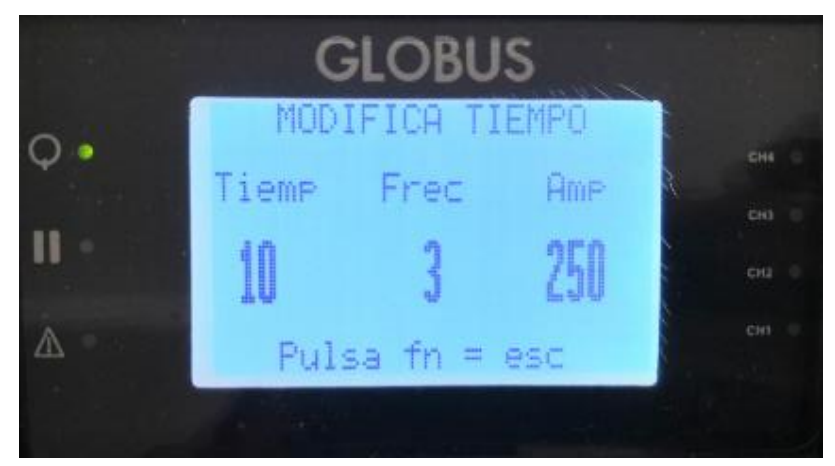

Figure 8 Programming of the electrostimulator: Low frequency TENS

Source: Self Made
The treatment was placed for 30 minutes, once a week for 3 months (14 weeks). The Oswestry questionnaire and the modified Schober test were applied prior to the start of the first session and at the end of the fourteenth treatment session. Regarding the perception of low back pain, before and after each treatment the patient was asked to indicate its intensity according to the numerical scale.

\section{Methodology}

Quantitative, non-experimental, retrospective, cross-sectional and descriptive type in patients with nonspecific chronic low back pain who attended the Physical Therapy and Rehabilitation service in the period between May 20 and August 22, 2019.

\section{Results}

A total of 15 people participated, in which the male sex prevailed with $53.3 \%$ having 8 participants for $46.6 \%$ of the female sex (7 participants); they had an age range of 19 to 58 years, the average age of the patients was 40.6 years.

\begin{tabular}{|l|l|l|}
\hline \multicolumn{3}{|c|}{ General patient data } \\
\hline & Total & Percentage \\
\hline Men & 8 & $53.3 \%$ \\
\hline Women & 7 & $46.6 \%$ \\
\hline Average age: 40.6 years \\
\hline
\end{tabular}

Table 1 General data

Source: Self Made

Regarding the classification of low back pain according to its possible origin, of the 15 patients who participated $11(73.3 \%)$ suffered from non-specific low back pain, 2 (13.3\%) low back pain associated with radiculopathy and the remaining $2(13.3 \%)$ had low back pain secondary.

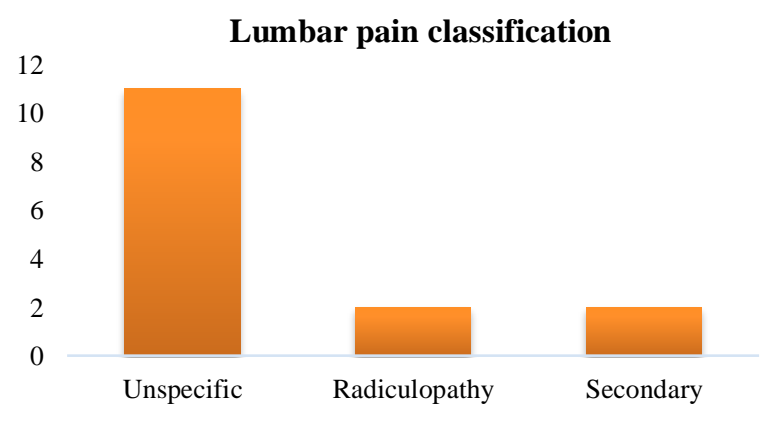

Graphic 1 Classification of low back pain according to its possible origin Source: Self Made 
Regarding the Oswestry low back pain disability scale, the questionnaire delivered prior to the first treatment session showed an average disability percentage of $21.73 \%$, at that time the highest record was 50\% and the lowest was $4 \%$. Three months later, at the end of the fourteenth treatment session, the highest percentage of disability was $10 \%$ and the lowest was $4 \%$, while the average was $3.6 \%$. That is, after the study, disability due to low back pain decreased on average $81.1 \%$ (table 2).

\begin{tabular}{|l|l|l|l|}
\hline \multicolumn{4}{|c}{ Oswestry low back pain disability scale } \\
\hline & $\begin{array}{l}\text { Initial } \\
\text { percentage }\end{array}$ & $\begin{array}{l}\text { Final } \\
\text { percentage }\end{array}$ & Improvement \\
\hline 1 & $8 \%$ & $0 \%$ & $100 \%$ \\
\hline 2 & $4 \%$ & $4 \%$ & $0 \%$ \\
\hline 3 & $28 \%$ & $4 \%$ & $85.7 \%$ \\
\hline 4 & $20 \%$ & $8 \%$ & $60 \%$ \\
\hline 5 & $32 \%$ & $2 \%$ & $93.7 \%$ \\
\hline 6 & $26 \%$ & $6 \%$ & $76.9 \%$ \\
\hline 7 & $50 \%$ & $10 \%$ & $80 \%$ \\
\hline 8 & $6 \%$ & $0 \%$ & $100 \%$ \\
\hline 9 & $30 \%$ & $10 \%$ & $66.6 \%$ \\
\hline 10 & $18 \%$ & $0 \%$ & $100 \%$ \\
\hline 11 & $38 \%$ & $0 \%$ & $100 \%$ \\
\hline 12 & $6 \%$ & $0 \%$ & $100 \%$ \\
\hline 13 & $20 \%$ & $4 \%$ & $80 \%$ \\
\hline 14 & $24 \%$ & $6 \%$ & $75 \%$ \\
\hline 15 & $16 \%$ & $0 \%$ & $100 \%$ \\
\hline Total & $21.7 \%$ & $3.6 \%$ & $81.1 \%$ \\
\hline & & & \\
\hline
\end{tabular}

Table 2 Percentages of the Oswestry low back pain disability scale

Source: Self Made

Regarding the modified Schober test, it was applied to each of the 15 participants prior to the first treatment session, the maximum registered mark was $19.8 \mathrm{~cm}$, while the minimum was $17.4 \mathrm{~cm}$; The average of the test was $18.84 \mathrm{~cm}$. Subsequently, once the last treatment session was completed, the minimum level recorded was $19.6 \mathrm{~cm}$ and the maximum was $23.9 \mathrm{~cm}$; The average showed a result of $21.75 \mathrm{~cm}$. That is, between the first and fourteenth treatment session, on average, there was an increase in lumbar mobility of $2.9 \mathrm{~cm}$ (table 3).

\begin{tabular}{|l|l|l|l|}
\hline \multicolumn{5}{|c|}{ Modified Schober Test } \\
\hline & $\begin{array}{l}\text { Initial } \\
\text { Mark (cm) }\end{array}$ & $\begin{array}{l}\text { Final mark } \\
(\mathbf{c m})\end{array}$ & $\begin{array}{l}\text { Increase in } \\
\text { cm }\end{array}$ \\
\hline 1 & $19.2 \mathrm{~cm}$ & $20 \mathrm{~cm}$ & $0.8 \mathrm{~cm}$ \\
\hline 2 & $19.8 \mathrm{~cm}$ & $21.7 \mathrm{~cm}$ & $1.9 \mathrm{~cm}$ \\
\hline 3 & $17.8 \mathrm{~cm}$ & $20.7 \mathrm{~cm}$ & $2.9 \mathrm{~cm}$ \\
\hline 4 & $19.2 \mathrm{~cm}$ & $23.7 \mathrm{~cm}$ & $4.5 \mathrm{~cm}$ \\
\hline 5 & $18 \mathrm{~cm}$ & $21.2 \mathrm{~cm}$ & $3.2 \mathrm{~cm}$ \\
\hline 6 & $19.1 \mathrm{~cm}$ & $23 \mathrm{~cm}$ & $3.9 \mathrm{~cm}$ \\
\hline 7 & $17.4 \mathrm{~cm}$ & $19.6 \mathrm{~cm}$ & $2.2 \mathrm{~cm}$ \\
\hline 8 & $19.8 \mathrm{~cm}$ & $21 \mathrm{~cm}$ & $1.2 \mathrm{~cm}$ \\
\hline
\end{tabular}

\begin{tabular}{|l|l|l|l|}
\hline 9 & $18.5 \mathrm{~cm}$ & $21.5 \mathrm{~cm}$ & $3 \mathrm{~cm}$ \\
\hline 10 & $19.3 \mathrm{~cm}$ & $22.6 \mathrm{~cm}$ & $3.3 \mathrm{~cm}$ \\
\hline 11 & $18.3 \mathrm{~cm}$ & $21 \mathrm{~cm}$ & $2.7 \mathrm{~cm}$ \\
\hline 12 & $19.1 \mathrm{~cm}$ & $23.9 \mathrm{~cm}$ & $4.8 \mathrm{~cm}$ \\
\hline 13 & $19.3 \mathrm{~cm}$ & $22.8 \mathrm{~cm}$ & $3.5 \mathrm{~cm}$ \\
\hline 14 & $18.9 \mathrm{~cm}$ & $21.4 \mathrm{~cm}$ & $2.5 \mathrm{~cm}$ \\
\hline 15 & $19 \mathrm{~cm}$ & $22.2 \mathrm{~cm}$ & $3.2 \mathrm{~cm}$ \\
\hline Average & $\mathbf{1 8 . 8 4} \mathbf{~ c m}$ & $\mathbf{2 1 . 7 5} \mathbf{~ c m}$ & $\mathbf{2 . 9} \mathbf{~ c m}$ \\
\hline
\end{tabular}

Table 3 Records of the modified Schober test Source: Self Made

Regarding the perception of low back pain, before and after each treatment session, each of the 15 participants was asked to indicate the intensity of the same according to the numerical scale. Prior to the start of the study, low back pain averaged an intensity of $7.1 / 10$; seven weeks later, in the middle of the study, pain perception decreased and averaged an intensity of $3.3 / 10$; finally, after the fourteenth treatment session, the intensity of low back pain showed an average of $1.3 / 10$ (graphic 2).

Lumbar pain intensity

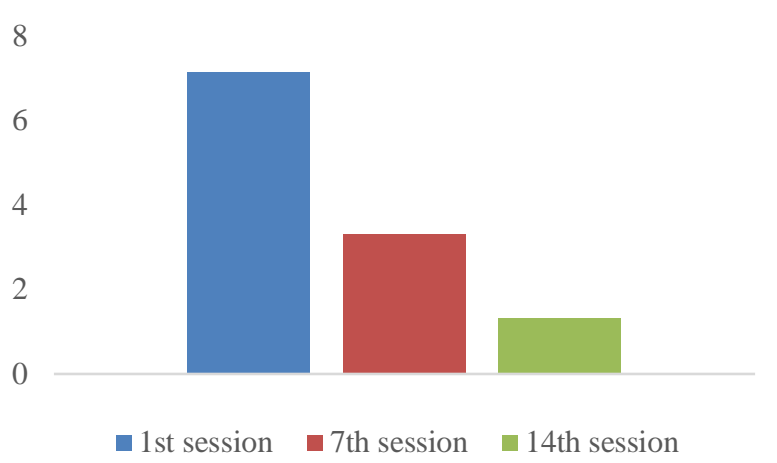

Graphic 2 Records of the intensity of low back pain according to the numerical scale Source: Self Made

Before the start of the study, each participant indicated the intensity of low back pain, based on the numerical scale, at that time the highest record was 10/10, while the lowest was $5 / 10$, the average was $7.1 / 10$. For half of the study, that is, seven sessions later, the maximum recorded intensity of low back pain was $6 / 10$ and the minimum was $1 / 10$; the patient with the lowest percentage of improvement registered an advance of $33.3 \%$, while the one with the greatest progress showed an improvement of $80 \%$. After 7 sessions, the perception of discomfort decreased on average $54.1 \%$ compared to the start of the study (table $4)$.

CORONA-BRISEÑO, Agustin. Proposed protocol with transcutaneous electrical nerve stimulation for the treatment of nonspecific chronic low back pain. ECORFAN Journal-Bolivia. 2019. 


\begin{tabular}{|l|l|l|l|}
\hline \multicolumn{4}{|c|}{ Lumbar pain intensity } \\
\hline & $\begin{array}{c}\text { First } \\
\text { session }\end{array}$ & $\begin{array}{c}\text { Seventh } \\
\text { session }\end{array}$ & $\begin{array}{c}\text { Percentage of } \\
\text { improvement }\end{array}$ \\
\hline $\mathbf{1}$ & $8 / 10$ & $4 / 10$ & $50 \%$ \\
\hline $\mathbf{2}$ & $5 / 10$ & $3 / 10$ & $40 \%$ \\
\hline $\mathbf{3}$ & $9 / 10$ & $4 / 10$ & $55.5 \%$ \\
\hline $\mathbf{4}$ & $6 / 10$ & $2 / 10$ & $66.6 \%$ \\
\hline $\mathbf{5}$ & $8 / 10$ & $3 / 10$ & $62.5 \%$ \\
\hline $\mathbf{6}$ & $7 / 10$ & $3 / 10$ & $57.1 \%$ \\
\hline $\mathbf{7}$ & $10 / 10$ & $6 / 10$ & $40 \%$ \\
\hline $\mathbf{8}$ & $6 / 10$ & $4 / 10$ & $33.3 \%$ \\
\hline $\mathbf{9}$ & $9 / 10$ & $6 / 10$ & $33.3 \%$ \\
\hline $\mathbf{1 0}$ & $5 / 10$ & $2 / 10$ & $60 \%$ \\
\hline $\mathbf{1 1}$ & $9 / 10$ & $3 / 10$ & $66.6 \%$ \\
\hline $\mathbf{1 2}$ & $6 / 10$ & $3 / 10$ & $50 \%$ \\
\hline $\mathbf{1 3}$ & $6 / 10$ & $2 / 10$ & $66.6 \%$ \\
\hline $\mathbf{1 4}$ & $8 / 10$ & $4 / 10$ & $50 \%$ \\
\hline $\mathbf{1 5}$ & $5 / 10$ & $1 / 10$ & $80 \%$ \\
\hline Average & $\mathbf{7 . 1}$ & $\mathbf{3 . 3}$ & $\mathbf{5 4 . 1 \%}$ \\
\hline \multicolumn{5}{|l}{} \\
\end{tabular}

Table 4 Records of the intensity of low back pain between the first and seventh week according to the numerical scale

Source: Self Made

The perception of low back pain before and after the study decreased considerably, initially the average intensity of discomfort, according to the numerical scale, was located at $7.1 / 10$, after three months (14 sessions) of treatment, low back pain averaged an intensity of $1.3 / 10$. The 15 participants showed improvement, pain decreased between 50\% and $100 \%$, on average, the perception of discomfort dropped $82.9 \%$ compared to the start of the study (table 5).

Lumbar pain intensity before and after the study

\begin{tabular}{|l|l|l|l|}
\hline & $\begin{array}{c}\text { First } \\
\text { session }\end{array}$ & $\begin{array}{c}\text { Last } \\
\text { session }\end{array}$ & $\begin{array}{c}\text { Percentage of } \\
\text { improvement }\end{array}$ \\
\hline $\mathbf{1}$ & $8 / 10$ & $0 / 10$ & $100 \%$ \\
\hline $\mathbf{2}$ & $5 / 10$ & $1 / 10$ & $80 \%$ \\
\hline $\mathbf{3}$ & $9 / 10$ & $3 / 10$ & $66.6 \%$ \\
\hline $\mathbf{4}$ & $6 / 10$ & $1 / 10$ & $83.3 \%$ \\
\hline $\mathbf{5}$ & $8 / 10$ & $1 / 10$ & $87.5 \%$ \\
\hline $\mathbf{6}$ & $7 / 10$ & $1 / 10$ & $85.7 \%$ \\
\hline $\mathbf{7}$ & $10 / 10$ & $5 / 10$ & $50 \%$ \\
\hline $\mathbf{8}$ & $6 / 10$ & $2 / 10$ & $66.6 \%$ \\
\hline $\mathbf{9}$ & $9 / 10$ & $3 / 10$ & $66.6 \%$ \\
\hline $\mathbf{1 0}$ & $5 / 10$ & $0 / 10$ & $100 \%$ \\
\hline $\mathbf{1 1}$ & $9 / 10$ & $0 / 10$ & $100 \%$ \\
\hline $\mathbf{1 2}$ & $6 / 10$ & $0 / 10$ & $100 \%$ \\
\hline $\mathbf{1 3}$ & $6 / 10$ & $1 / 10$ & $83.3 \%$ \\
\hline $\mathbf{1 4}$ & $8 / 10$ & $2 / 10$ & $75 \%$ \\
\hline $\mathbf{1 5}$ & $5 / 10$ & $0 / 10$ & $100 \%$ \\
\hline Average & $\mathbf{7 . 1}$ & $\mathbf{1 . 3}$ & $\mathbf{8 2 . 9 \%}$ \\
\hline
\end{tabular}

Table 5 Records of the intensity of low back pain at the beginning and end of the study according to the numerical scale

Source: Self Made

\section{Conclusions}

The application of high and low frequency Transcutaneous Electrical Nerve Stimulation in the same session is effective in the treatment of nonspecific chronic low back pain as it increases lumbar mobility, decreases the intensity of pain and therefore the degree of disability of patients.

TENS is useful for this condition in the short and long term, the phenomenon of tolerance to said therapeutic current was not evident.

\section{References}

Álvarez Araújo, N. (2016). Efectividad del tratamiento mediante la técnica músculo energía (MET) aplicada al psoas-ilíaco en el dolor lumbar crónico en taxistas.

Cameron, M. (2019). Agentes físicos en rehabilitación. Práctica basada en la evidencia. Barcelona: ELSEVIER.

Fernández-Tenorio, E., Serrano-Muñoz, D., Avendaño-Coy, J., \& Gómez-Soriano, J. (2016). Estimulación eléctrica nerviosa transcutánea como tratamiento de la espasticidad: una revisión sistemática. Neurología.

Jiménez-Ávila, J. M., Rubio-Flores, E. N., González-Cisneros, A. C., Guzmán-Pantoja, J. E., \& Gutiérrez-Román, E. A. (2018). Directrices en la aplicación de la guía de práctica clínica en la lumbalgia. Cirugía y Cirujanos, 86(1), 29-37.

Masselli, M. R., Fregones, C. E. P. T., de Faria, C. R. S., Bezerra, M. I. S., Junges, D., \& Nishioka, T. H. (2017). Índice funcional de oswestry após cirurgia para descompressão de raízes nervosas. Fisioterapia em Movimento, 20(1).

Mojica, H. M. B., Parra, J. E. D., \& Cortés, F. J. C. P. (2017). Variaciones del rango de flexión lumbar en una muestra poblacional sana de niños y niñas escolares caldenses (Colombia). Medicina, 39(3), 181-189.

Ortíz, F. (2016). Texto de medicina física y rehabilitación. Editorial El Manual Moderno Colombia SAS. 
Serrano-Muñoz, D., Gómez-Soriano, J., ÁvilaMartín, G., Galán-Arriero, I., Romero-Muñoz, L. M., Taylor, J. S., \& Barriga-Martín, A. (2016). Sensibilización central al dolor en pacientes con síndrome del latigazo cervical: una revisión. Revista Latinoamericana de Cirugía Ortopédica, 1(3), 102-107.

Vance, C. G., Dailey, D. L., Rakel, B. A., \& Sluka, K. A. (2014). Using TENS for pain control: the state of the evidence. Pain management, 4(3), 197-209.

Varangaonkar, V. C., Ganesan, S., \& Kumar, K. V. (2015). The relationship between Lumbar range of motion with hamstring flexibility among 6-12 years children from South India: A cross-sectional study. International Journal of Health \& Allied Sciences, 4(1), 23.

Vicente-Herrero, M. T., Delgado-Bueno, S., Bandrés-Moyá, F., \& Capdevilla-García, L. (2018). Valoración del dolor. Revisión comparativa de escalas y cuestionarios. Revista de la Sociedad Española del Dolor, 25(4), 228236.

Villanueva Estrada, E. M., Hernández Bedolla, I., \& González Pedraza Avilés, A. (2015). Efectividad del tratamiento láser con ejercicio vs tens con ejercicio en la lumbalgia inespecífica. Revista Cubana de Medicina Física y Rehabilitación, 7(2), 116-123. 